\title{
E-Learning Adoption and Acceptance in Pakistan: Moderating Effect of Gender and Experience
}

\author{
Faria Kanwal $^{1}$, Mariam Rehman ${ }^{2}$, Malik Muhammad Asif ${ }^{3}$ \\ RECEIVED ON 27.12.2018, ACCEPTED ON 19.02.2019
}

\begin{abstract}
With the rapid growth of ICT (Information and Communication Technologies), the traditional educational system has been restructured into e-learning systems. E-learning adoption and acceptance is in rudimentary stages of development in Pakistan. Therefore, it is imperative to understand and evaluate the critical factors of technology adoption and acceptance considering the moderating effect of individual differences (gender and experience) based on Technology Acceptance Model. Quantitative analysis was conducted on 356 learners from the Virtual University of Pakistan. Structural Equation Modelling was used to test research models. The results illustrate that the perception of and intention to adopt technology are highly dependent on gender and experience in using e-learning systems. Computer anxiety and social influence are significant predictors of elearning adoption in female learners whereas social influence and enjoyment is significant predictors in less experienced learners than more experienced learners.
\end{abstract}

Key Words: E-Learning Adoption, E-Learning Adoption in Pakistan, Individual Differences (Gender, Experience), Perception and Intention to Use,

\section{INTRODUCTION}

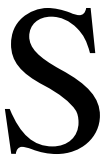
ince 1990, the class room based educational infrastructure has been restructured into innovative and effective learning and teaching practices. E-learning is considered to be the premier mode of knowledge sharing and disseminating [1]. E-learning is considered as an information system that provides learning contents to learners by using communication medium [2]. Elearning is used to encourage learning and teaching, and for delivering course content regardless of geographical precincts. The tremendous benefits offered by e-learning are cost-effective learning, flexibility in time management, self-paced learning and interactive learning (ibid). Moreover, e-learning is becoming more popular among educational institutions that intend to reap the maximum benefits from this new paradigm.

E-learning as a mode of enhancing the infrastructure of traditional education has initiated a knowledgebased and globalised society. The worldwide market for e-learning has shown significant expansion [2].

\footnotetext{
${ }^{1}$ Department of Computer Science, Lahore College for Women University, Lahore, Pakistan.

Email: faria.kanwal@gmail.com (Corresponding Author)

${ }^{2}$ Department of Information Technology, Government College University, Faisalabad, Pakistan.

Email: dr.mrehman13@gmail.com

${ }^{3}$ Department of Computer Science, National Textile University, Faisalabad, Pakistan. Email: asi135@ gmail.com

This is an open access article published by Mehran University of Engineering and Technology, Jamshoro under CC BY 4.0 International License. 
The nation in academic excellence has successfully integrated digital technologies in HEIs (Higher Education Institutions). Developed countries have successfully met the challenges by implementing, improving, and promoting the digitization of education while HEIs in developing countries are still facing challenges in their development and implementation. Developing countries interpret elearning as the foremost strategy to embrace the development of their economy and compete with developed countries [3]. The feeling of segregation among developing countries has decreased to a noteworthy degree with the assistance of e-learning.

Researchers have evaluated and recommended essential steps to overcome the barriers to e-learning integration in developing countries. Moreover, the digital divide gap between developed and developing countries has been discussed. The digital divide gap is explained in various ways from technological issues to individual differences intrinsic to e-learning development and enactment. Learners' negative attitude, sense of isolation, and low level of computer literacy depend on individual differences.

Pakistan, being a developing country, focuses on improving the traditional educational structure by amalgamating advanced technologies. According to the census, the population of Pakistan is 207.8 million. Among the stated population, 2.71 and $9.18 \%$ of the population have progressed to higher education in rural and urban areas respectively. Access to basic and higher education has been continuously denied in the country. Basically, education is given a low priority with an expenditure of only $2 \%$ of the GDP (Gross Domestic Product) allocated for it [4]. Consequently, the literacy rate has declined by $2 \%$ in 2017 . The literacy rates for males and females are 70 and $49 \%$ respectively.

To rectify the miserable scenario, the GoP (Government of Pakistan) has revised regulations to boost ICT by providing the low cost internet in the country.

Basically, phenomena of technology adoption have been evaluated on macro level and micro level. At macro level, societal norms and its influence is focused to maximize individual attitude towards future use. Moreover, cultural factors have been examined on national-level and organizational-level. Organizational level culture is predicted by examining barriers associated with technology accessibility, communication of learners and learners' expected behavior. Whereas, considering micro level, individual's attitude is investigated. A scarcity of administrative and technical facilities, difference in cultural and economic situation and societal influence are prominent hindrances in Pakistan. Similarly, considering the learners perspective, lack of perception and awareness towards adoption of modern paradigm of learning, deficiency of resources in underprivileged areas, dearth of financial resources in rural areas, and low levels of computer literacy are major challenges from the learners' perspective in Pakistan. Moreover, Contextual factors are also important to incorporate e-learning in the educational institutions of Pakistan. Furthermore, user factor, social, technological and cultural issues must be investigated on a priority basis [5].

Adoption and acceptance of technology face several challenges stated above. However, problems arise when systems are not designed with the learners' perspective in mind. Successful implementation of e- 
learning depends on the proper design of system based on the learners' perspective, when the availability of these systems is no longer a matter of concern. Therefore, in this research social influence and organizational level culture in terms of organizational accessibility is focused to encounter socio-cultural drivers at macro level. Moreover, personal characteristics of learners are focused at micro level. The way that learners' use technology depends highly on their attitude and some external factors (personal, system characteristics, organizational accessibility and societal influence) that predict learners' intention. Furthermore, individual differences (gender, experience, age) pose great challenges in similar cultural environments. Gender differences and level of technological expertise have also been identified as critical in the adoption and acceptance of technology [3].

In information system research, a number of theoretical models have been identified and evaluated in diverse cultural settings. TRA (Theory of Reasoned Action), TPB (Theory of Planned Behavior), TAM (Technology Acceptance Model) and UTAUT (Unified Theory of Acceptance and Use of Technology) are commonly used models. All the models have their own advantages and limitations. TRA and TPB predict behavior on some specific criteria. Moreover, it is difficult to group constructs for facilitating conditions in UTAUT. However, among these models, the TAM is accepted as robust model to predict intention in e-learning systems use. To predict learners' intention, TAM has been tested and validated in developed western countries [6]. Subsequently, TAM with critical factors has been investigated in different states to predict behavioral intention phenomenon. Later on, the power of evaluation of
TAM was augmented by including individual differences as moderators [7]. The influence of individual differences is notable to analyze the phenomenon of adoption profoundly [8].

In e-learning adoption and acceptance, individual differences (gender and experience) are found dominant moderators. Although, gender-based assessment is not found statistically significant in [9], and authors of [10] arrived at the conclusion that perception of male learners is higher than female. In contrast, another study found that usage intention in female learners is slightly higher than in male learners engage in e-learning systems [11]. Moreover, gender differences also affect the measurement of critical success factors-personal and societal - that lead to successful adoption of technology [12]. In the similar manner, adoption phenomenon enriched with prior experience. It increases with the increase in experience [13]. Therefore, evidence regarding individual differences in technology adoption is not conclusive.

The literature depicts insufficient research in investigating individual differences in the context of Pakistan. Therefore, this study investigates role of individual differences (gender and experience) on the critical success factors of e-learning adoption and acceptance. The critical success factors that are considered for this study were: personal characteristics of learners (self-efficacy, computer anxiety, enjoyment and internet experience), organizational accessibility, system characteristics (system response, system interactivity, system functionality) and social influence.

To conduct this study, the following RQ (Research Questions) are formulated 
RQ1: What is the effect of individual differences (moderating variables) on critical success factors (personal characteristics, system characteristics, social influence and organizational accessibility)?

RQ2: Is Technology Acceptance Model valid for elearning adoption and acceptance in a non-western country? OR

Is Technology Acceptance Model biased for elearning adoption and acceptance in western countries?

This study will provides valuable insight and enriched the literature for two basic reasons: 1) a consideration of the above-mentioned shortcomings in information system literature in Pakistan and 2) to better understand the individual differences (gender, experience) to explain technology adoption and acceptance in Pakistan with greater depth. These individual variables have their own importance in adoption and acceptance. Moreover, these findings explain the bias of TAM for or against non-western developing countries like Pakistan.

\section{THEORATICAL BACKGROUND AND HYPOTHESES DEVELOPMENT}

This section discusses the conceptual research model and development of hypotheses in detail.

\subsection{Research Model and Hypotheses}

Fig. 1 depicts the research model used in this study. Gender and experience-based analyses are conducted to comprehensively expose the critical factors that influence the adoption and acceptance of e-learning in the context of Pakistan.

\subsection{Gender}

The literature related to e-learning adoption and acceptance is deepened by addition of moderating variables such as gender [10-11]. The TAM has been enriched by $52 \%$ when introducing gender as moderator [7]. Though, perception and intention of elearning systems may depend on gender but the literature showed no conclusive evidences in this regard. Prior research showed noteworthy differences for male and female in critical success factors of technology adoption and acceptance [8].

It was observed and concluded that females are less confident though spent more time and involve in online activities than male[12]. Another significant findings showed that the anxious level of females are higher than male learners in adoption of Web 2.0 usage [14].

Furthermore, gender based analysis reported that BI depend on PU and PEOU are stronger in males in the adoption of e-learning systems [8]. Later on, another study conducted in Brazil analyzed that intention and usage behavior is more prevalent in male rather in female [10]. On contrary, the dominant behavior and attitude of female learners is reported higher than male learners [11].

Moreover, it is also recorded that educational excellence and prospects are not gender-dependent. Therefore, the absence of gender differences is also found in adoption and acceptance of e-learning systems [15].

\subsection{Experience}

Experience as moderator has been paid significant attention in the continued use of e-learning systems. 
The prior experience may boost learners' perception relationship of constructs among TAM has been and behavior of using e-learning systems [13]. The moderated by inclusion of prior experience. It was

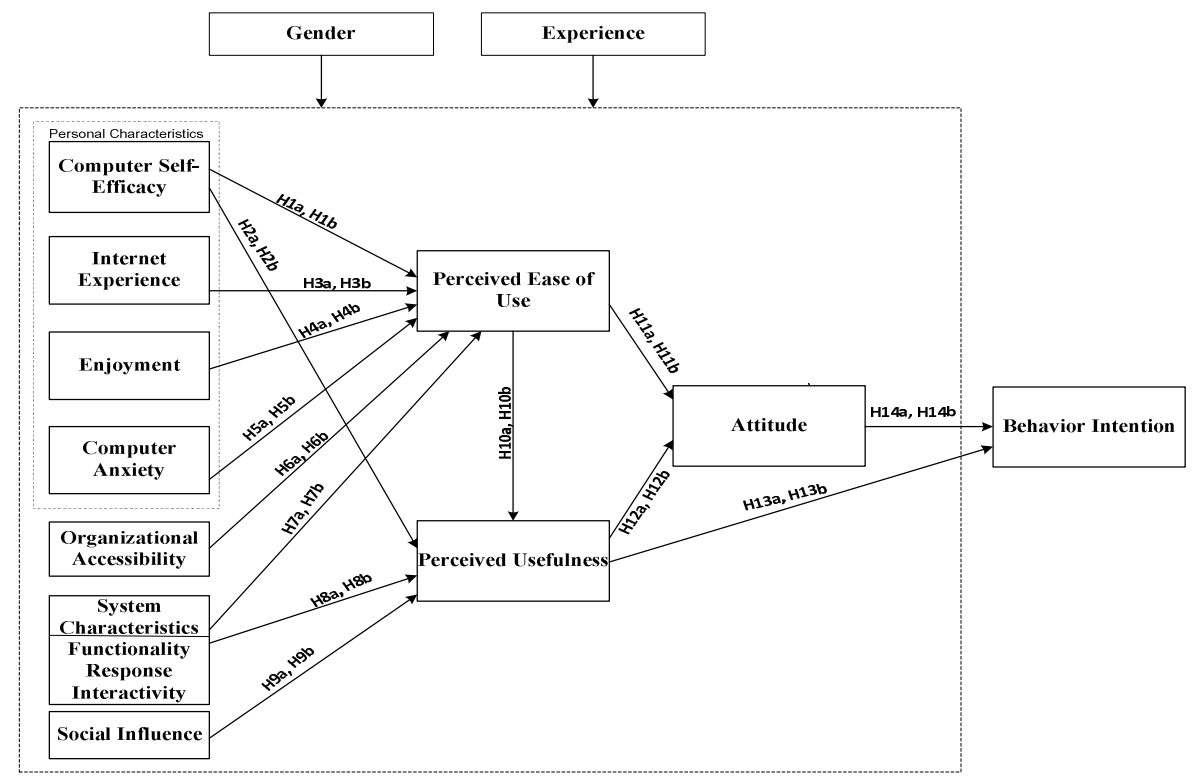

FIG. 1. CONCEPTUAL RESEARCH MODEL

observed that ease of use is not major concern for more experienced learners compared to inexperienced learners [6]. It was also observed that societal impact is higher for inexperienced or less experienced users than for more experienced users [7]. The literature has also concluded that PU and PEOU becomes nominal over time due to experience in technology usage.

Based on the facts and inconclusive evidences, this study investigates the moderating effect of gender and prior experience in predicting behavior based on critical success factors of technology adoption in Pakistan. Fig. 1 depicts the research model used in this study.

\subsection{Model Constructs}

\subsubsection{Moderating Role of Gender and} Experience on Computer Self-Efficacy

CSE (Computer Self-Efficacy) is considered as an individual's evaluation of their capabilities and selfconfidence to accomplish computer-related activities while using computer systems [16]. CSE has been consistently studied and proven as a key predictor of e-learning acceptance and continued use (ibid). Previous research verified the presence of gender differences in CSE. It was concluded that female learners are less confident and have lesser self-efficacy than male learners [17]. Subsequently, CSE is also moderated by previous experience of technology [18]. More experienced learners are more willing to accept the concept of usefulness and found no difficulty in using e-learning systems compared to less experienced learners, whereas less experienced learners are attracted to and concerned by PEOU.

H1a: The effect of CSE on PEOU is moderated by gender in the adoption of e-learning systems.

H1b: The effect of CSE on PEOU is moderated by experience in the adoption of e-learning systems.

H2a: The effect of CSE on PU is moderated by gender in the adoption of e-learning systems. 
H2b: The effect of CSE on PU is moderated by experience in the adoption of e-learning systems.

\subsubsection{Moderating Role of Gender and Experience on Internet Experience}

IE (Internet Experience) plays a significant role in predicting intention towards online learning. Studies depict that the behavioral intention of using e-learning increases with the increase in ease of internet navigation, communication technologies, and selfconfidence in performing online activities [16].

It is statistically evident that female learners are less motivated towards e-learning than male learners are [16]. Male learners communicate, collaborate, and are able to manage online activities more effortlessly than female learners can.

Similarly, the prior experience significantly predicts learners' behavior towards future use. The empirical results concluded that less experienced learners are less motivated in adopting and accepting modern technologies compared to more experienced learners. Moreover, learners with more understanding of technology utilized online learning systems more effortlessly than less experienced learners [19].

H3a: The effect of IE on PEOU is moderated by gender in the adoption of e-learning systems.

H3b: The effect of IE on PEOU is moderated by experience in the adoption of e-learning systems.

\subsubsection{Moderating Role of Gender and Experience on Enjoyment}

The most influential factor in learning is enjoyment. Literature indicates that the pleasant feeling of using the system is enjoyment [7]. Engaging learners and appealing to their sense of performing fun-related activities significantly predict the motivation and intention in e-learning systems [16].

Moreover, research indicated greater difference considering pleasant feeling of male and female learners while using e-learning systems. The results showed significant gender difference between male and female learners [20]. Enjoyment directly enhances the intention of male learners to use e-learning systems whereas it affects intention via attitude in female learners. It was also verified that user friendly and pleasing systems considerably affect both more experienced and less experienced learners.

H4a: The effect of Enjoyment on PEOU is moderated by gender in the adoption of elearning system.

H4b: The effect of Enjoyment on PEOU is moderated by experience in the adoption of e-learning system.

\subsubsection{Moderating Role of Gender and Experience on Computer Anxiety}

Negative feelings, apprehension, and fear of making mistakes in computer-related activities are referred to as computer anxiety [16]. Computer anxiety makes it difficult for users to perform well in e-learning systems.

The studies predicts that level of anxiety in male learners is much lower than in female learners. Female learners are less confident, less optimistic and eventually more apprehensive than male learners in 
internet usage. The results based on Web 2.0 technologies revealed that female learners are more apprehensive and higher level of anxiety than male learners [14].

Similarly, even in this digital era, computer anxiety still exists in less experienced learners. The relevant studies depicts that lack of experience in new technologies may cause edginess and uneasiness. Experience significantly affect learners' positive attitude towards modern paradigm of education [21].

H5a: The effect of CA on PEOU is moderated by gender in the adoption of e-learning system.

H5b: The effect of CA on PEOU is moderated by experience in the adoption of e-learning system.

\subsubsection{Moderating Role of Gender and Experience on Organizational Accessibility}

The availability and support of organizations (educational institutes and universities) for online learning is termed as organizational accessibility (OA). Easy access of required software, computer hardware, speedy internet and other related resources may lead to greater behavioral intention towards elearning systems. With the increasing trend of computer and internet, learners irrespective of gender and experience difference have their own equipment and have same facilities to involve in online activities. The results depicts that female learners and male learners both have same prospect in gaining access to computers [20]. The increasing trend of having computer have decreased problems in computer accessibility.

H6a: The effect of OA on PEOU is moderated by gender in adoption of e-learning system.
H6b: The effect of OA on PEOU is moderated by experience in adoption of e-learning system.

\subsubsection{Moderating Role of Gender and Experience on System Characteristics}

The importance of system characteristics is evaluated and validated by the successful adoption and acceptance of IS literature. System characteristics are an integrated term explained by system functionality, interactivity, and response. Empirical evidence depicts that flexibility in performing learning activities, integration of different multimedia resources (text, audio, and video), and appropriate responses from elearning systems significantly enhances adoption and acceptance [22].

Females have a more promising attitude towards website functionality than males. Furthermore, it was concluded that easy to use and stress-free system functionalities are of importance to females (ibid). System characteristics can affect the learners' ease of use rather than usefulness in a professional environment. E-learning system characteristics can provide ease of learning, but not usefulness.

The research study depicts the significant differences between less experienced and more experienced users considering usability of e-learning systems. However, no gender-based and experience-based differences are found in terms of usability and interactive environment [23].

H7a: The effect of SC on PEOU is moderated by gender in the adoption of e-learning system.

H7b: The effect of SC on PEOU is moderated by experience in the adoption of e-learning system.

H8a: The effect of SC on PU is moderated by gender in the adoption of e-learning system.

Mehran University Research Journal of Engineering and Technology, Vol. 39, No. 2, April 2020 [p-ISSN: 0254-7821, e-ISSN: 2413-7219] 
H8b: The effect of SC on PU is moderated by experience in the adoption of e-learning system.

\subsubsection{Moderating Role of Gender and Experience on Social Influence}

The opinion or perception of society or individuals (family, friends, peers or instructors) who are important to learners are termed as Social Influence (SI). The research study depicts that motivation and inspiration from society exerts pressure to anticipate usage behavior of learners.

Empirical evidences suggest that SI predict usage intention for female learners is stronger compared to male learners [6].

Discussing prior experience, it was observed and investigated that prior knowledge, familiarity with systems and awareness establish strong perception for more experienced learners rather than less experienced learners (ibid).

H9a: The effect of SI on PU is moderated by gender in the adoption of e-learning system.

H9b: The effect of SI on PU is moderated by experience in the adoption of e-learning system.

\subsubsection{Moderating Role of Gender and Experience on Perceived Ease of Use and Perceived Usefulness}

Perceived Ease of Use is the degree of an individual's surety that using a system will be effort-free. Considering the gender based analysis, it was observed and concluded that PU is influenced by PEOU in male compared to female [24]. Contrary to above findings, no gender difference is found on BI via PEOU whereas stronger correlation is found for less experienced learners [6]. Therefore, it is concluded that ease of use is not subject to more experienced learners due to awareness, knowledge, skill and expertise.

Perceived Usefulness is the degree of an individual's surety that using a system will increase professional development. Studies indicated that PU is a significant predictor of attitude and intention to use system.

Discussing gender differences in describing PU, it is confirmed that usefulness significantly affect intention in female learners compared to male learners[24]. In contrast, another research identified that female learners are less practical and less professionaloriented, hence usefulness is not subjective to adoption of e-learning systems for female [6]. In the same way, previous research have validated that usefulness is not concern for more experienced learners compared to less experienced learners (ibid).

H10a: The effect of PEOU on PU is moderated by gender in the adoption of e-learning system.

H10b: The effect of PEOU on PU is moderated by experience in the adoption of e-learning system.

H11a: The effect of PU on BI is moderated by gender in the adoption of e-learning system.

H11b: The effect of PU on BI is moderated by experience in the adoption of e-learning system.

\subsubsection{Moderating Role of Gender and} Experience on Attitude towards BI

Attitude is an individual's positive or negative flair for e-learning systems [24]. Previous findings showed significant gender difference in perception and usage intention. More positive attitude exhibits in male 
learners compared to female learners [25]. Furthermore, previous experience significantly affect BI. Learners having prior experience showed different attitude towards technology use compared to less experienced learners. Learner's attitude in adopting and accepting e-learning systems increases with the increase in experience.

H12a: The effect of PEOU on Attitude is moderated by gender in the adoption of e-learning system.

H12b: The effect of PEOU on Attitude is moderated by experience in the adoption of e-learning system.

H13a: The effect of PU on Attitude is moderated by gender in the adoption of e-learning system.

H13b: The effect of PU on Attitude is moderated by experience in the adoption of e-learning system.

H14a: The effect of Attitude on BI is moderated by gender in the adoption of e-learning system.

H14b: The effect of Attitude on BI is moderated by experience in the adoption of e-learning system.

\subsection{Research Methodology}

To investigate the research hypotheses, quantitative research approach is used. Participants are identified and data is collected. The constructs is adopted from literature studies.

\subsubsection{Research Participants and Data Collection}

An analysis was conducted on the data collected from students of the Virtual University of Pakistan enrolled in graduate and postgraduate levels of Business Studies, Commerce, Information Technology, and Department of Computer Science, Lahore College for Women University, Lahore Computer Science disciplines to investigate research hypotheses. Learners using e-learning systems were chosen and the data were obtained from purposive sampling method. An online questionnaire in English was uploaded on the official website of VUP and it used the five-point Likert scale for analyzing the responses. Three hundred and fifty-six valid responses were collected for data analysis. We analyzed the data using a statistical approach. SPSS 21.0 was employed to calculate reliability, validity, and factor loading. Amos 20.0 was used to investigate and compare the differences between the two groups for each moderator. The maximum likelihood method was adopted to estimate and compare the two groups considering the individual differences of the respondents.

\subsubsection{Operationalization of Constructs}

The questionnaire comprised of two sections. The first section consisted of respondents' demographic profile and it was measured using the nominal scale, whereas the second section consisted of critical factors and constructs of TAM to be evaluated in e-learning adoption, acceptance, and usage intention.

\section{RESULTS AND DISCUSSION}

This section focuses on the empirical analysis of data and results are presented. A SEM (Structural Equation Model) technique is used to measure the relationship between latent constructs and variables. This technique is best suited to test hypotheses and validity of conceptual model. Furthermore, a detail interpretation and significance of results are explained in discussion section.

\subsection{Data Analysis Results 3.1.1 Respondents' Descriptive Analysis}

Table 1 depicts the descriptive statistics of the respondents. Of the participants, $71 \%$ are male learners and $29 \%$ are female learners; and $72 \%$ learners are less experienced while $28 \%$ learners are more experienced. The next section focuses on a 
measurement model to examine reliability and validity. Then the hypotheses are tested and the structural model is analyzed.

\begin{tabular}{|c|c|c|}
\hline \multirow{2}{*}{ TABLE 1. DESCRIPTIVE STATISTICS } \\
\hline \multirow{2}{*}{ Gender } & Male & 255 \\
\cline { 2 - 3 } Experience & $\begin{array}{c}\text { Female } \\
\text { More Experienced } \\
\text { (more than 3 years) }\end{array}$ & 101 \\
\cline { 2 - 3 } & $\begin{array}{c}\text { Less Experienced } \\
\text { (1-3 years) }\end{array}$ & 98 \\
\hline \multirow{2}{*}{ Education } & Graduate & 184 \\
\cline { 2 - 3 } & Post graduate & 172 \\
\hline
\end{tabular}

\subsubsection{Results of the Measurement Model}

A SEM is applied to examine measurement and structural models. Prior to examine the measurement model, convergent validity and internal consistency of the constructs were measured. To examine internal consistency, Cronbach's $\alpha$ was used and achieved the recommended value (Cronbach's $\alpha>0.70$ ). Cronbach's $\alpha$ was used to measure the internal consistency and reliability of the constructs. It is used to measure the closeness of set of constructs as a
Moreover, AVE (Average Variance Extracted) and CR (Composite Reliability) are measured to achieve convergent validity. All constructs satisfied the recommended value (AVE $>0.40)$ and $(\mathrm{CR}>0.60)$.

Moreover, EFA (Exploratory Factor Analysis) was performed to verify that each individual item loads into its corresponding construct group. Principal component analysis with varimax rotation (suppressing values $<0.40$ ) was applied. Table 2 depicts the results of convergent validity, internal consistency and FL (Factor Loading) values of each item.

\subsubsection{Results of the Structural Model}

After analysis of the measurement model hypotheses are examined considering individual differences (gender, experience). The hypothesized model are accessed for fit indices. Table 3 depicts fit indices of the hypothesized model for both groups. The values satisfied the recommended values of fit indices. Moreover, Figs. 2--5 illustrate the structural models for both groups. group.

\begin{tabular}{|c|c|c|c|c|c|}
\hline \multicolumn{6}{|c|}{ TABLE 2. RELIABILITY, CONVERGENT VALIDITY, AND FACTOR ANALYSIS } \\
\hline Items & $\begin{array}{l}\text { Reliability, Validity and } \\
\text { Factor Loading }\end{array}$ & Male & Female & More Experienced & $\begin{array}{l}\text { Less Experi } \\
\text { enced }\end{array}$ \\
\hline \multirow{7}{*}{$\begin{array}{l}\text { Computer } \\
\text { Self-Efficacy }\end{array}$} & AVE & 0.46 & 0.44 & 0.43 & 0.41 \\
\hline & CR & 0.80 & 0.79 & 0.79 & 0.76 \\
\hline & Cronbach's $\alpha$ & 0.70 & 0.76 & 0.67 & 0.74 \\
\hline & FL & & & & \\
\hline & CSE1 & 0.76 & 0.72 & 0.50 & 0.72 \\
\hline & CSE2 & 0.74 & 0.66 & 0.78 & 0.66 \\
\hline & CSE3 & 0.54 & 0.60 & 0.67 & 0.51 \\
\hline \multirow{8}{*}{ Internet Experience } & AVE & 0.52 & 0.50 & .52 & 0.59 \\
\hline & CR & 0.88 & 0.87 & .88 & 0.88 \\
\hline & Cronbach's $\alpha$ & 0.81 & 0.80 & .81 & 0.81 \\
\hline & FL & & & & \\
\hline & IE1 & 0.76 & 0.76 & 0.64 & 0.00 \\
\hline & IE2 & 0.83 & 0.81 & 0.75 & 0.78 \\
\hline & IE3 & 0.62 & 0.55 & 0.72 & 0.79 \\
\hline & IE4 & 0.67 & 0.68 & 0.78 & 0.73 \\
\hline \multirow{7}{*}{ Enjoyment } & AVE & 0.41 & 0.41 & 0.53 & 0.33 \\
\hline & CR & 0.77 & 0.77 & 0.85 & 0.69 \\
\hline & Cronbach's $\alpha$ & 0.89 & .89 & 0.91 & 0.88 \\
\hline & $\mathrm{FL}$ & & & & \\
\hline & Enj1 & 0.60 & 0.60 & 0.73 & 0.53 \\
\hline & Enj2 & 0.71 & 0.71 & 0.78 & 0.68 \\
\hline & Enj3 & 0.59 & 0.59 & 0.68 & 0.49 \\
\hline \multirow{6}{*}{ Computer Anxiety } & AVE & 0.78 & 0.79 & .77 & 0.80 \\
\hline & $\mathrm{CR}$ & 0.95 & 0.95 & .95 & 0.96 \\
\hline & Cronbach's $\alpha$ & 0.88 & 0.92 & .87 & 0.89 \\
\hline & FL & & & & \\
\hline & CA1 & 0.85 & 0.86 & 0.84 & 0.88 \\
\hline & CA2 & 0.91 & 0.92 & 0.92 & 0.92 \\
\hline
\end{tabular}


E-Learning Adoption and Acceptance in Pakistan: Moderating Effect of Gender and Experience

\begin{tabular}{|c|c|c|c|c|c|}
\hline & CA3 & 0.89 & 0.87 & 0.87 & 0.88 \\
\hline \multirow{12}{*}{$\begin{array}{c}\text { System } \\
\text { Characteristics }\end{array}$} & AVE & 0.50 & 0.50 & 0.54 & 0.45 \\
\hline & $\mathrm{CR}$ & 0.88 & 0.92 & 0.93 & 0.91 \\
\hline & Cronbach's $\alpha$ & 0.89 & 0.88 & 0.87 & 0.89 \\
\hline & $\begin{array}{l}\text { FL } \\
\text { SF1 }\end{array}$ & 0.49 & 0.56 & 0.50 & 0.53 \\
\hline & SF2 & 0.62 & 0.79 & 0.88 & 0.69 \\
\hline & SF3 & 0.49 & 0.74 & 0.78 & 0.65 \\
\hline & SR1 & 0.54 & 0.77 & 0.73 & 0.71 \\
\hline & SR2 & 0.67 & 0.76 & 0.46 & 0.79 \\
\hline & SR3 & 0.62 & 0.74 & 0.66 & 0.76 \\
\hline & SI1 & 0.54 & 0.76 & 0.71 & 0.65 \\
\hline & SI2 & 0.60 & 0.55 & 0.81 & 0.56 \\
\hline & $\mathrm{SI} 3$ & 0.54 & 0.00 & 0.55 & 0.00 \\
\hline \multirow{7}{*}{ Social Influence } & AVE & 0.58 & 0.63 & 0.59 & 0.60 \\
\hline & $\mathrm{CR}$ & 0.88 & 0.90 & 0.88 & 0.89 \\
\hline & Cronbach's $\alpha$ & 0.86 & 0.89 & 0.86 & 0.87 \\
\hline & FL & & & & \\
\hline & SI1 & 0.76 & 0.78 & 0.76 & 0.76 \\
\hline & SI2 & 0.79 & 0.81 & 0.84 & 0.79 \\
\hline & $\mathrm{SI} 3$ & 0.75 & 0.79 & 0.69 & 0.78 \\
\hline \multirow{7}{*}{$\begin{array}{c}\text { Organizational } \\
\text { Accessibility }\end{array}$} & AVE & 0.52 & 0.27 & 0.42 & 0.44 \\
\hline & $\mathrm{CR}$ & 0.84 & 0.63 & 0.78 & 0.79 \\
\hline & Cronbach's $\alpha$ & 0.76 & 0.83 & 0.79 & 0.78 \\
\hline & FL & & & & \\
\hline & OA1 & 0.63 & 0.47 & 0.66 & 0.69 \\
\hline & OA2 & 0.76 & 0.55 & 0.55 & 0.68 \\
\hline & OA3 & 0.75 & 0.54 & 0.72 & 0.61 \\
\hline \multirow{6}{*}{$\begin{array}{c}\text { Perceived Ease of } \\
\text { Use }\end{array}$} & AVE & 0.52 & 0.41 & 0.44 & 0.47 \\
\hline & CR & 0.76 & 0.76 & 0.78 & 0.72 \\
\hline & Cronbach's $\alpha$ & 0.74 & 0.76 & 0.79 & 0.72 \\
\hline & $\begin{array}{c}\text { FL } \\
\text { PEOU1 }\end{array}$ & & & & \\
\hline & PEOU1 & 0.49 & $\begin{array}{l}0.79 \\
0.44\end{array}$ & $\begin{array}{l}0.90 \\
0.49\end{array}$ & 0.85 \\
\hline & PEOU3 & 0.53 & $\begin{array}{l}0.44 \\
0.45\end{array}$ & $\begin{array}{l}0.49 \\
0.53\end{array}$ & 0.45 \\
\hline \multirow{6}{*}{$\begin{array}{l}\text { Perceived } \\
\text { Usefulness }\end{array}$} & AVE & 0.69 & 0.57 & 0.59 & 0.70 \\
\hline & $\mathrm{CR}$ & 0.93 & 0.87 & 0.88 & 0.93 \\
\hline & Cronbach's $\alpha$ & 0.93 & 0.91 & 0.94 & 0.92 \\
\hline & $\begin{array}{l}\text { F.L } \\
\text { PUU }\end{array}$ & & & & \\
\hline & PU1 & 0.84 & 0.78 & 0.75 & 0.85 \\
\hline & $\begin{array}{l}\text { PU2 } \\
\text { PU3 }\end{array}$ & $\begin{array}{l}0.85 \\
0.80\end{array}$ & $\begin{array}{l}0.74 \\
0.74\end{array}$ & $\begin{array}{l}0.83 \\
0.73\end{array}$ & $\begin{array}{l}0.87 \\
0.80\end{array}$ \\
\hline \multirow{8}{*}{ Attitude } & AVE & 0.50 & 0.44 & 0.40 & 0.45 \\
\hline & $\mathrm{CR}$ & 0.84 & 0.78 & 0.80 & 0.79 \\
\hline & Cronbach's $\alpha$ & 0.71 & 0.77 & 0.766 & 0.71 \\
\hline & FL & & & & \\
\hline & ATT1 & 0.77 & 0.79 & 0.82 & 0.81 \\
\hline & ATT2 & 0.00 & 0.43 & 0.46 & 0.45 \\
\hline & ATT3 & 0.65 & 0.54 & 0.61 & 0.57 \\
\hline & ATT4 & 0.69 & 0.63 & 0.59 & 0.61 \\
\hline \multirow{6}{*}{ BI } & AVE & 0.30 & 0.30 & 0.26 & 0.26 \\
\hline & $\mathrm{CR}$ & 0.57 & 0.55 & 0.51 & 0.51 \\
\hline & Cronbach's $\alpha$ & 0.82 & 0.85 & 0.84 & 0.83 \\
\hline & FL & & & & \\
\hline & BI1 & 0.54 & 0.47 & 0.49 & 0.49 \\
\hline & BI2 & 0.56 & 0.59 & 0.52 & 0.51 \\
\hline
\end{tabular}

\begin{tabular}{|c|c|c|c|c|}
\hline \multicolumn{5}{|c|}{ TABLE 3. FIT INDICES } \\
\hline \multirow{2}{*}{ Gender } & Male & $\chi 2 / \mathrm{df}(<5)$ & CFI $(>0.90)$ & NFI $(>0.90)$ \\
\cline { 2 - 5 } & Female & 4.343 & 0.959 & 0.947 \\
\hline \multirow{2}{*}{ Experience } & More Experienced & 1.764 & 0.978 & 0.954 \\
\cline { 2 - 5 } & Less Experienced & 4.646 & 0.967 & 0.956 \\
\hline
\end{tabular}




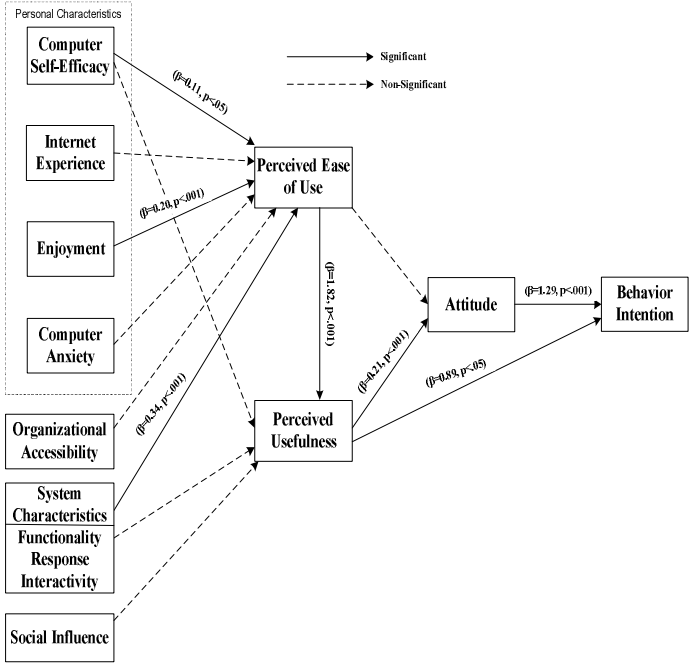

FIG. 2. STRUCTURAL MODEL FOR MALE LEARNERS

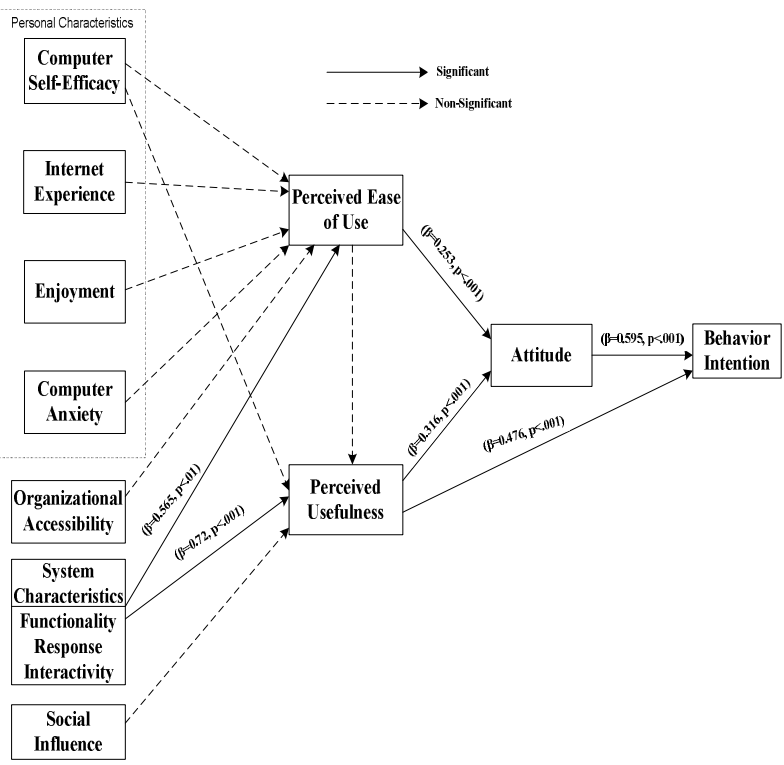

\section{FIG. 4. STRUCTURAL MODEL FOR MORE EXPERIENCED LEARNERS}

The results of hypothesized models are shown in Tables 4-5 for gender-based and experience-based analysis respectively.

The empirical evidence significantly describe differences in predicting intention. The critical factors that predict BI for both groups of each moderating variables (gender, experience) are different in elearning adoption and acceptance.

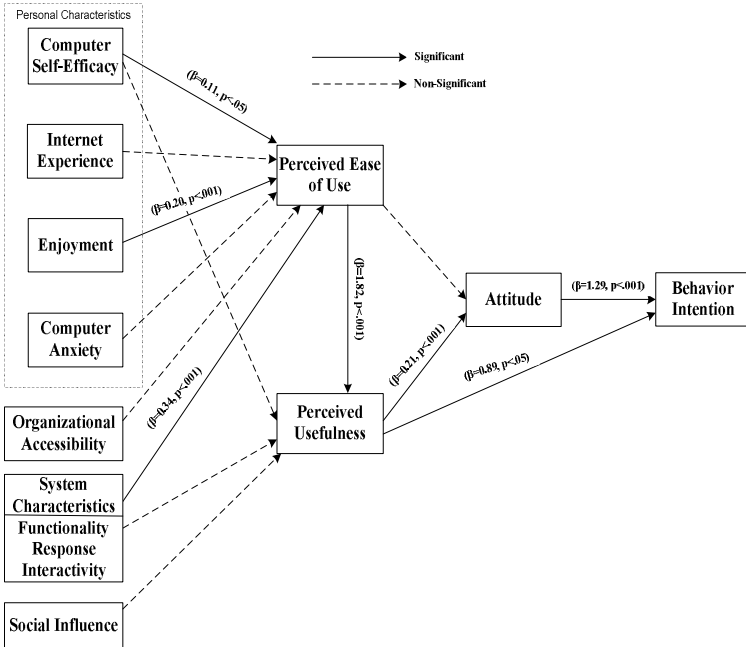

FIG. 3. STRUCTURAL MODEL FOR FEMALE LEARNERS

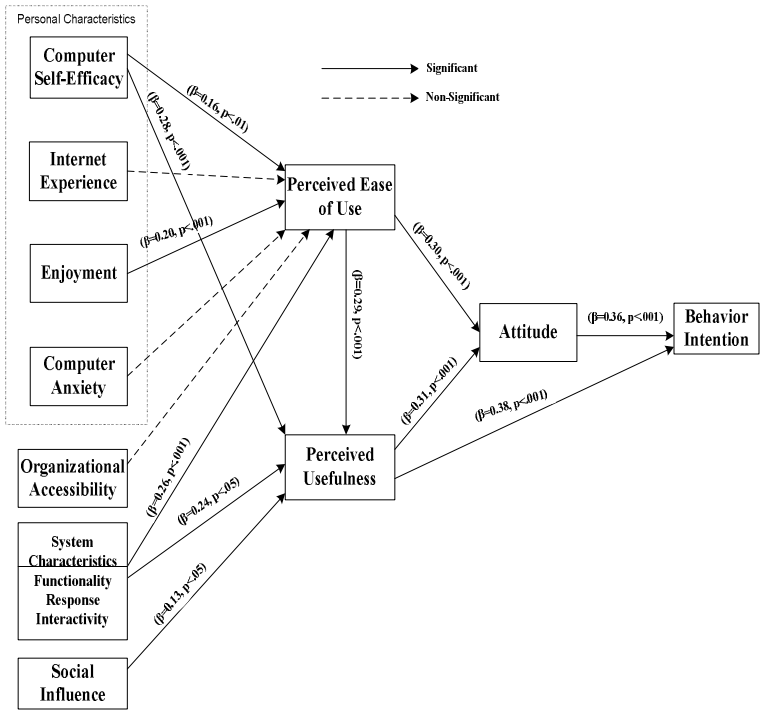

FIG. 5. STRUCTURAL MODEL FOR LESS EXPERIENCED LEARNERS

The empirical evidences proved that female learners are influenced by computer anxiety, computer selfefficacy, and social influence. However, enjoyment and system characteristics are significant factors for both male and female learners. Similarly, system characteristics is significant predictor to measure BI for both more experienced and less experienced learners. Furthermore, main constructs of TAM is also moderated by individual differences. The results are discussed in detail in discussion section. 


\begin{tabular}{|c|c|c|c|c|c|c|}
\hline \multicolumn{7}{|c|}{ TABLE 4: HYPOTHESES RESULTS BASED ON GENDER } \\
\hline \multirow{2}{*}{ Hypotheses } & \multicolumn{3}{|c|}{ Male } & \multicolumn{3}{|c|}{ Female } \\
\hline & $\mathrm{B}$ & $\begin{array}{c}\text { Significant } \\
\text { (p) }\end{array}$ & Result & $\mathrm{B}$ & $\begin{array}{c}\text { Significant } \\
\text { (p) }\end{array}$ & Result \\
\hline H1a & 0.11 & 0.05 & $\mathrm{~S}$ & 0.08 & 0.11 & NS \\
\hline $\mathrm{H} 2 \mathrm{a}$ & -0.08 & 0.511 & NS & 0.13 & 0.02 & $\mathrm{~S}$ \\
\hline $\mathrm{H} 3 \mathrm{a}$ & 0.01 & 0.724 & NS & 0.08 & 0.15 & NS \\
\hline $\mathrm{H} 4 \mathrm{a}$ & 0.20 & $* * *$ & $S$ & 0.24 & $* * *$ & $S$ \\
\hline $\mathrm{H} 5 \mathrm{a}$ & 0.01 & 0.582 & NS & 0.07 & 0.02 & $S$ \\
\hline H6a & 0.02 & 0.316 & NS & 0.00 & 0.91 & NS \\
\hline $\mathrm{H} 7 \mathrm{a}$ & 0.34 & $* * *$ & $S$ & 0.29 & 0.001 & $S$ \\
\hline $\mathrm{H} 8 \mathrm{a}$ & 0.32 & 0.194 & NS & 0.43 & $* * *$ & $S$ \\
\hline H9a & 0.05 & 0.126 & NS & 0.16 & 0.003 & $S$ \\
\hline $\mathrm{H} 10 \mathrm{a}$ & 1.82 & $* * *$ & $S$ & 0.25 & $* * *$ & $S$ \\
\hline H11a & 0.21 & 0.042 & $S$ & 1.152 & $* * *$ & $S$ \\
\hline $\mathrm{H} 12 \mathrm{a}$ & 0.03 & 0.611 & NS & 1.11 & $* * *$ & $\mathrm{~S}$ \\
\hline $\mathrm{H} 13 \mathrm{a}$ & 0.89 & $* * *$ & $S$ & 0.10 & 0.144 & NS \\
\hline $\mathrm{H} 14 \mathrm{a}$ & 1.29 & $* * *$ & $S$ & -0.01 & 0.92 & NS \\
\hline \multicolumn{7}{|c|}{ Note: $\mathrm{p}<.001, \mathrm{p}<.01, \mathrm{p}<.05$ where $\mathrm{S}=$ Supported, and NS=Not Supported } \\
\hline
\end{tabular}

\begin{tabular}{|c|c|c|c|c|c|c|}
\hline \multicolumn{7}{|c|}{ TABLE 5: HYPOTHESES RESULTS BASED ON EXPERIENCE } \\
\hline \multirow[b]{2}{*}{ Hypotheses } & \multicolumn{3}{|c|}{ More Experienced } & \multicolumn{3}{|c|}{ Less Experienced } \\
\hline & B & $\begin{array}{l}\text { Significant } \\
\text { (p) }\end{array}$ & Result & B & $\begin{array}{c}\text { Significant } \\
\text { (p) }\end{array}$ & Result \\
\hline $\mathrm{H} 1 \mathrm{~b}$ & 0.16 & 0.077 & NS & 0.16 & 0.005 & $\mathrm{~S}$ \\
\hline $\mathrm{H} 2 \mathrm{~b}$ & 0.046 & 0.637 & NS & 0.28 & $* * *$ & $\mathrm{~S}$ \\
\hline $\mathrm{H} 3 \mathrm{~b}$ & -0.05 & 0.568 & NS & 0.07 & 0.177 & NS \\
\hline $\mathrm{H} 4 \mathrm{~b}$ & 0.157 & 0.063 & NS & 0.20 & $* * *$ & $S$ \\
\hline $\mathrm{H} 5 \mathrm{~b}$ & 0.08 & 0.151 & NS & -0.03 & 0.268 & NS \\
\hline H6b & -0.03 & 0.698 & NS & -0.02 & 0.664 & NS \\
\hline $\mathrm{H} 7 \mathrm{~b}$ & 0.565 & $* * *$ & $S$ & 0.26 & $* * *$ & $S$ \\
\hline $\mathrm{H} 8 \mathrm{~b}$ & 0.72 & $* * *$ & $S$ & 0.24 & 0.002 & $\mathrm{~S}$ \\
\hline $\mathrm{H} 9 \mathrm{~b}$ & 0.128 & 0.159 & NS & 0.13 & 0.013 & $S$ \\
\hline $\mathrm{H} 10 \mathrm{~b}$ & 0.171 & 0.134 & NS & 0.29 & $* * *$ & $S$ \\
\hline $\mathrm{H} 11 \mathrm{~b}$ & 0.253 & 0.001 & $S$ & 0.30 & $* * *$ & $S$ \\
\hline $\mathrm{H} 12 \mathrm{~b}$ & 0.316 & $* * *$ & $\mathrm{~S}$ & 0.31 & $* * *$ & $\mathrm{~S}$ \\
\hline $\mathrm{H} 13 \mathrm{~b}$ & 0.476 & $* * *$ & $S$ & 0.38 & $* * *$ & $\mathrm{~S}$ \\
\hline $\mathrm{H} 14 \mathrm{~b}$ & 0.595 & $* * *$ & $S$ & 0.36 & $* * *$ & $S$ \\
\hline \multicolumn{7}{|c|}{ Note: $\mathrm{p}<.001, \mathrm{p}<.01, \mathrm{p}<.05$ where $\mathrm{S}=$ Supported, and NS=Not Supported } \\
\hline
\end{tabular}

\subsubsection{Discussion}

This study intended to explore individual differences (gender, experience) in predicting behavioral intention in e-learning systems. The conceptual research model is investigated using multi-group analysis considering moderating variables (gender and experience) in the context of Pakistan. This research has observed and concluded significant differences in predicting intention of critical factors of adopting e-learning systems.
CSE on PU significantly affect in female learners whereas the effect of CSE on PEOU is not moderated by gender. The male learners reported higher levels of CSE and showed higher performance in basic and challenging computer-related activities compared to female learners. CSE does not predict the male learners' intention through PEOU and PU. In this digital era, female learners are competing with male learners. The findings are consistent with previous research [26]. Hence, female learners are inclined to use technology if the usage of computers enhances 
professional and career development. CSE is a significant predictor of PEOU and PU in less experienced learners. These findings are consistent with [27]. PEOU in less experienced learners is a significant predictor. When learners find an e-learning system easy to use as well as useful, they are attracted to and involved with it. CSE is insignificant in more experienced learners. The findings are consistent with prior research [1]. Performance and satisfaction increase with increase in literacy and advanced skills but have no influence in the intention of adoption of elearning.

Internet experience is not found to be significantly moderated by gender and experience, thus rejecting the hypotheses $\mathrm{H} 3 \mathrm{a}$ and $\mathrm{H} 3 \mathrm{~b}$. The growing internet infrastructure and users since 1990 in Pakistan have reduced the effect of the internet experience in technology adoption.

Enjoyment is a significant predictor of PEOU in both male and female learners causing them to adopt elearning systems, thus supporting hypothesis H4a. The findings are consistent with the results of previous research by [20]. Enjoyment is significant irrespective of gender differentiation. With regard to the factor of experience, enjoyment plays a positive role for less experienced learners and exhibits no significant impact on more experienced learners. The results are consistent with the studies of (ibid). Non-technical learners, either male or female, are motivated and influenced by systems that offer scope for entertainment. If e-learning systems succeed in engaging and attracting learners, this factor significantly predicts their future intention to use these systems. The designers have to design systems with attractive, appealing, and pleasing interfaces for learners. The course contents and information should be presented using various multimedia (text, audio, and video) approaches to attract learners.

The effect of computer anxiety on PEOU is found to be significant for female learners but not for male learners. The results validate previous work [12]. The researchers found that females are more anxious and feel more apprehensive compared to male learners. HEIs should organize basic-level training for female learners to increase their computer-related skills. Furthermore, experience does not moderate the relationship between computer anxiety and PEOU. The findings are similar to [21]. HEIs' learners, having experience in a lesser or greater degree, are not afraid of using computers. Negative discernment affects initial perception and decreases over time.
Hypotheses H6a and $\mathrm{H} 6 \mathrm{~b}$ are insignificant. Organizational accessibility is not moderated by gender or experience. The Government of Pakistan has initiated regulatory policies to encourage learners and assist the emergence of innovative technology in traditional infrastructure. This reduces the barriers challenging the access to computers and the internet. The Virtual University of Pakistan is equipped with ICT resources. The advanced infrastructure and access to resources all over Pakistan has reduced the concern of accessibility. Hence, HEIs' management should assimilate and focus on the infrastructure required to motivate learners towards e-learning systems.

System Characteristics are found to be significant and strong predictors of PEOU moderated by both gender and experience. The results are consistent with [23]. System usability, interactivity, functionality, and response significantly affect learners' ease of use irrespective of individual differences (gender and experience). Designers and developers should not only design an appealing system but the system should be sound and respond appropriately. Moreover, the elearning system should provide well-organized and interactive learning materials having audio and visual aids. Learners' feelings of isolation decrease when facilities like discussion boards and chat rooms are readily available and pro-active. Systems should offer learner control to facilitate learners. In contrast, the PU in male learners is not dependent on system characteristics. The usefulness of e-learning is not a concern when this technology is not job-related. Hence, it is accepted that male learners are more joboriented since they have diverse jobs. Thus, the usefulness of technology may have no significance in their professional and career development. However, HEIs have to build and implement well-designed systems to attract and encourage learners.

This research investigated the effect of moderating variables (gender and experience) on SI. While SI has no effect on male learners, it is a significant predictor in female learners. Male learners exhibit greater awareness and understanding and make quicker decisions to adopt technology compared to female learners. Females are more influenced by the opinions of others than males are. The results are consistent with the earlier findings of [6]. Similarly, it was observed that less experienced learners are more influenced by society than more experienced learners are. The results support the study conducted by [28] in a different cultural setting. More experienced learners are not influenced by the perceptions of others. They believe in their knowledge and prior experiences with technology. Society influences new entrants. Hence,

Mehran University Research Journal of Engineering and Technology, Vol. 39, No. 2, April 2020 [p-ISSN: 0254-7821, e-ISSN: 2413-7219] 
academicians should play positive roles in providing comfort and ease for new entrants to enhance their perceptions and intentions for future use of technology.

Intention is significantly predicted by the core constructs of PEOU and PU via attitude. The learners' perception of external critical factors displayed a strong relationship with PEOU and PU moderated by gender and experience. The intention of male learners is significantly predicted by PU and PEOU since PU indirectly affects the attitude. Moreover, PU is also a direct predictor of intention in male learners. The results are consistent with earlier research by [6]. Whereas PEOU is correlated to attitude in female learners, PU is the direct determinant of $\mathrm{BI}$ in them. The findings support previous literature [27]. PU is stronger in males and PEOU is stronger in females via attitude. Male learners are more career-oriented and professionally committed. Therefore, policy makers and experts must strongly convey the benefits of adopting new technology for prospective professional growth to attract more learners.

On the other hand, PU is a significant core construct of predicting intention in more experienced and less experienced learners. Attitude is not predicted by PEOU in less experienced learners while it is the direct determinant of attitude in more experienced learners; and PU is not affected by PEOU in more experienced learners. The results are consistent with prior research by [27]. PEOU and PU strongly predict attitude and intention moderated by experience. These results offer guidelines for developers, designers, and policy makers to design systems that can be adopted easily and help learners achieve their career goals. Furthermore, learners' perceptions of the usefulness and ease of use of e-learning systems to perform efficiently and enhance skills and competencies in professional development are moderated by gender and experience. The findings indicated TAM as a successful model to predict learners' intention. TAM has also been proven as a robust theoretical model of e-learning adoption in developing countries. Innovative virtual education technologies help to improve learning and progressively benefit the educational systems in Pakistan.

The results presented in this section is important to improve technology adoption phenomena in HEIs specifically for Pakistan. This paper has examined difference and contradictory views of critical success factors of technology adoption focusing individual differences of e-learning in HEIs of Pakistan. The indepth analysis of difference in gender and experience, minimize access barriers for effectively utilize modern paradigm of learning. Moreover, understanding of critical factors based on gender and experience help to maximize adoption towards future use by reducing gender discrimination and enhancing experience as well. Policy makers, practitioners, designers and developers could have benefited to overcome critical factors which hinders adoption and usage.

\subsubsection{Contributions}

In summation, this study uniquely contributes in the following ways: First, this study augments previous studies that considered and highlighted the role of moderating variables (gender and experience) in the adoption and acceptance of technology. The effect of moderating variables enriched TAM and highlighted greater individual differences (gender and experience) in accepting and adopting technology. This study provides conclusive evidence of critical factors and individual differences in terms of gender and experience. The findings are consistent with previous research where individual differences are shown to exist in western/ non-western countries [10], [24] and they also contradict the findings of [15], [23] who postulated that no individual differences exist in terms of gender or experience.

Second, this study provides a greater insight of TAM considering individual differences in a culturally diverse setting of developing countries, more precisely Pakistan. This study minimizes the bias of TAM for western countries that was criticized by [29-30].

Third, this study suggested practical implications for stakeholders of e-learning systems. System characteristics play a significant role for learners irrespective of gender and experience bias. Designers and developers have to plan, design, and implement user-friendly, learner-controlled, and responsive systems. These findings also inspire HEIs to implement a well-organized system to entice more learners. Moreover, HEIs should have training sessions for female and less experienced entrants to reduce anxiety and enhance self-efficacy. SI is an influential factor for female and less experienced learners. We recommend that management and faculty encourage and persuade learners towards using computer-related tasks prior to their admittance in classes of higher education. Furthermore, PU and PEOU play positive roles in the adoption and acceptance of e-learning. Learners' intention increases when the system benefits them in knowledge progression as well as career development. This research concluded that HEIs and the Government 
should promote quality education using e-learning for better future and career development [31].

Finally, this study concedes a wide gap in the quantitative investigation of e-learning adoption and acceptance considering individual characteristics (gender and experience) in the context of Pakistan. Assessment and empirical evidence explore, identify and prioritize the crucial factors of e-learning adoption, acceptance, and intention specifically based on individual characteristics in Pakistan.

\section{CONCLUSION}

E-learning offers better solutions to the learning process and benefits learners in under-privileged regions as well. The foremost objective of this study to explore the effect of individual characteristics (gender and experience) in the adoption and acceptance of e-learning in Pakistan was fulfilled.

TAM can become an appropriate theoretical model of technology adoption by the addition of external critical factors moderated by gender and experience in Pakistan. The results showed remarkable individual differences in the critical factors for e-learning adoption. Female learners are more anxious and more susceptible to social influence than male learners are. Similarly, less experienced learners are more affected by social influence compared to more experienced learners. Moreover, gender and experience have the deepest impact on the factor of system characteristics. Core constructs, PEOU, and PU were found to be significant in measuring attitude and intention, directly or indirectly, in e-learning acceptance.

\section{ACKNOWLEDGEMENT}

First of all, the authors are sincerely thanks to Higher Education Commission of Pakistan, for providing research facilities to Ph.D. Scholars. The authors are obliged to the management of Virtual University of Pakistan, for facilitating in data collection from distant learners. Authors also acknowledge Lahore College for Women University, Lahore, Pakistan, for providing research environment to complete this research work.

\section{REFERENCES}

[1] Kim, B. and Park, M. J., "Effect of personal factors to use ICTs on e-learning adoption: comparison between learner and instructor in developing countries", Information Technology for Development, Volume 23, No. 1, pp. 1-27, 2017.

[2] dos Santos, L. M. Renda and Okazaki, S., "Planned e-learning adoption and occupational socialisation in Brazilian higher education", Studies in Higher Education, Volume 41, No. 11, pp. 1974-1994, 2016.

[3] Ali, S., Uppal, M., and Gulliver, S., "A conceptual framework highlighting elearning implementation barriers", Information Technology \& People, Volume 31, No. 1, pp. 156-180, 2017.

[4] Farooq, M. S. and Kai, Y. T., "A review of Pakistan school system", Journal of Education and Practice, Volume 8, No. 4, pp. 97-101, 2017.

[5] Farid, S., Ahmad, R., and Alam, M., "A Hierarchical Model for E-learning Implementation Challenges using AHP", Malaysian Journal of Computer Science, Volume 28, No. 3, pp. 166-188, 2015.

[6] Tarhini, A., Hone, K., and Liu, X., "The effects of individual differences on e-learning users' behaviour in developing countries: A structural equation model", Computers in Human Behavior, Volume 41, pp. 153-163, 2014.

[7] Venkatesh, V., Morris, M. G., Davis, G. B., and Davis, F. D., "User Acceptance of Information Technology: Toward a Unified View", Management Information Systems, Volume 27, No. 3, pp. 425-478, 2003.

[8] Harvey, H. L., Parahoo, S., Bin, H., and Smart, M., "Should Gender Differences be Considered When Assessing Student Satisfaction in the Online Learning Environment for Millennials?", Higher Education Quarterly, Volume 71, No. 2, pp. 141-158, 2017.

[9] Arenas-gaitán, J., Javier Rondán-cataluña, F., and Ramírez-Correa, P. E., "Modelling the 
success of learning management systems: application of latent class segmentation using FIMIX-PLS", Interactive Learning Environments, Volume 26, No. 1, pp. 135$147,2017$.

[10] Okazaki, S. and dos Santos, L. M. R., "Understanding E-Learning Adoption in Brazil: Major Determinants and Gender Effects", The International Review of Research in Open and Distance Learning, Volume 13, No. 4, pp. 91-106, 2012.

[11] Chinyamurindi, W. and Shava, H., "An investigation into e-learning acceptance and gender amongst final year students", South African Journal of Information Management, Volume 17, No. 1, pp. 1-9, 2015.

[12] Agboola, A. K., "A Study of Sociodemographics Effects on E-Learning Adoption among Lecturers", International Journal of Emerging Technology and Advanced Engineering, Volume 3, No. 4, pp. 651-661, 2013.

[13] Abdullah, F. and Ward, R., "Developing a General Extended Technology Acceptance Model for E-Learning (GETAMEL) by analysing commonly used external factors", Computers in Human Behavior, Volume 56, pp. 238-256, 2016.

[14] Huang, W. D., Hood, W. D., and Yoo, S. J., "Internet and Higher Education Gender divide and acceptance of collaborative Web 2 . 0 applications for learning in higher education", The Internet and Higher Education, Volume 16, No. 1, pp. 57-65, 2013.

[15] Arenas-Gaitán, J., Rondan-cataluña, F. J., and Ramirez-correa, P. E., "Gender Influence in Perception and Adoption of E-Learning Platforms", Advances in Data Networks, Communications, Computers, pp. 30-35, 2010.

[16] Alenezi, A. R., Karim, A. M. A., and Veloo, A., "An empirical investigation into the role of enjoyment, computer anxiety, computer self-efficacy and internet experience in influencing the students' intention to use e learning: A case study from saudi arabian governmental universities", Turkish Online
Journal of Educational Technology, Volume 9, No. 4, pp. 22-34, 2010.

[17] Huffman, A. H., Whetten, J., and Huffman, W. H., "Using technology in higher education: The influence of gender roles on technology self-efficacy", Computers in Human Behavior, Volume 29, No. 4, pp. 1779-1786, 2013.

[18] Paraskeva, F., Bouta, H., and Papagianni, A., "Individual characteristics and computer self-efficacy in secondary education teachers to integrate technology in educational practice", Computers and Education, Volume 50, No. 3, pp. 1084-1091, 2008.

[19] Venkatesh, V., "Determinants of Perceived Ease of Use: Integrating Control, Intrinsic Motivation, and Emotion into the Technology Acceptance Model", Information Systems Research, Volume 11, No. 4, pp. 342-365, 2000.

[20] Padilla-meléndez, A., Aguila-obra, A. R., and Garrido-moreno, A. "Perceived playfulness , gender differences and technology acceptance model in a blended learning scenario", Computers \& Education, Volume 63, pp. 306-317, 2013.

[21] Mac Callum, K., Jeffrey, L., and Kinshuk, "Comparing the role of ICT literacy and anxiety in the adoption of mobile learning", Computers in Human Behavior, Volume 39, pp. 8-19, 2014.

[22] Imhof, M., Vollmeyer, R., and Beierlein, C., "Computer use and the gender gap: The issue of access, use, motivation, and performance", Computers in Human Behavior, Volume 23, No. 6, pp. 2823-2837, 2007.

[23] Lee, M. C., "Explaining and predicting users' continuance intention toward e-learning: An extension of the expectation-confirmation model", Computers and Education, Volume 54, No. 2, pp. 506-516, 2010.

[24] Thowfeek, M. H. and Salam, M. N. A., "Students' Assessment on the Usability of Eleaming Websites", Procedia - Social and Behavioral Sciences, Volume 141, pp. 916922, 2014.

[25] Ramírez-correa, P. E., Arenas-gaitán, J., and Rondán-catalu, F. J., "Gender and 
Acceptance of E-Learning: A Multi-Group Analysis Based on a Structural Equation Model among College Students in Chile and Spain”, PLOS One, No. 2, pp. 1-17, 2015. Buabeng-Andoh, C., "Factors influencing teachers ' adoption and integration of information and communication technology into teaching: A review of the literature Charles Buabeng-Andoh", International Journal of Education and Development using Information and Communication Technology, Volume 8, No. 1, pp. 136-155, 2012.

[27] Rohatgi, A., Scherer, R., and Hatlevik, O. E., "The role of ICT self-efficacy for students' ICT use and their achievement in a computer and information literacy test", Computers and Education, Volume 102, pp. 103-116, 2016.

[28] Tarhini, A., Hone, K., and Liu, X., "Measuring the Moderating Effect of Gender and Age on E-Learning Acceptance in
England: A Structural Equation Modeling Approach for An Extended Technology Acceptance Model", Journal of Educational Computing Research, Volume 51, No. 2, pp. 163-184, 2014.

[29] Tarhini, A., Hone, K., Liu, and Tarhini, T., "Examining the moderating effect of individual-level cultural values on users' acceptance of E-learning in developing countries: a structural equation modeling of an extended technology acceptance model", Interactive Learning Environments, Volume 25, No. 3, pp. 306-328, 2017.

[30] Bandyopadhyay, K. and Fraccastoro, K. A., "The Effect of Culture on User Acceptance of Information Technology.", Communications of the Association for Information Systems, Volume 19, No. April, pp. 522-543, 2007. 